\title{
Comparing Logit, Probit and Multiple Discriminant Analysis Models in Predicting Bankruptcy of Companies
}

\author{
Khalili Araghi, Maryam \\ Department of Business Management, Science and Research Branch \\ Islamic Azad University, Tehran, Iran
}

Tel: 98-912-217-2635Ｅ-mail: m.khaliliaraghi@gmail.com

\begin{abstract}
Makvandi, Sara (Corresponding author)
Department of Accounting, Science and Research Branch, Islamic Azad University

Sistan and Baluchestan, Zahedan, Iran
\end{abstract}

Tel: 98-916-621-6032 E-mail: saramakvandi@ymail.com

Received: December 31, 2012 Accepted: January 16, 2013 Published: June 1, 2013

doi:10.5296/ajfa.v5i1.2977 URL: http://dx.doi.org/10.5296/ajfa.v5i1.2977

\begin{abstract}
Experimental studies across the world show that one of investors and other activists' expectations in capital market is their ability in predicting the status of activity consistency or the bankruptcy of the companies. For this purpose, this study tries to predict the bankruptcy likelihood of manufacturing firms and comparing the predictability power of 3 methods of Logit, Probit, and Multiple-discriminant analysis. Statistical population of the study included all manufacturing firms listed in Stock Exchange of Tehran since 2000-2010.

The results showed that the predictability of Logit, Probit, and Multiple-dliscriminant models has been 81,80 , and $\% 70$ respectively. The results also showed the higher predictability and accuracy of Logit model and also Multiple discriminant analysis methods identify bankrupt firms with high accuracy in the level logit model.
\end{abstract}

Keywords: Bankruptcy, Logit model, Probit model, Multiple-discriminant model 


\section{Introduction}

Predicting bankruptcy has been a challenging issue for many scientific studies during the last 3 decades (Ching-Ching Yeh et al.2010). Bankruptcy is important in financial studies since its consequences affect the economy of the country. In fact, bankruptcy prediction has been very important for variety of public and commercial organizations. Because the failure of a company leads spread of crisis to other parts of the financial system and cause systemic crisis (Tonatiuh Pena et al.2009).

Unreliability from survival of the existing company in Stock Exchange is one of the factors that may discourage investment in the Stock Exchange, because perhaps bankrupt company in the same year, and is out of stock. Therefore with the design and propose appropriate patterns for forecasting firms that are going bankruptcy, Can be gave the investors this assurance to invest in stock market with the lower risk (Rekabdar et al,2006 ).

Many firms get bankrupt annually because such situations:

1. They have to sell their properties with low price.

2. Conflicts among creditors may delay liquidating the assets. Then the probability of physical damage and inventory depreciation increases.

3. A part of company value is spent for lawyers' fee, court cost, and organizational expenses which are not as important as 1 and 2 .

Regarding these cases, bankruptcy cost is high. It just occurs for the companies which have debt.

The companies lacking debt have never been bankrupt. So, financial provisions through debts causes increase in bankruptcy likelihood and reduce earnings. As a result, the likelihood of value decrease enhances because of the costs of bankruptcy. Increasing bankruptcy likelihood reduces the current value of the company, enhancing its capital costs (Brigam,2003).

Therefore it seems necessary to find a model that can predict the financial crisis and bankruptcy of companies. Statistical techniques are considered as the most basic and common techniques in bankruptcy prediction. This model has been used from classic standard modeling techniques and has focused on signs business failure. Generally, the variables used in Building these models is the information contained in the financial statements (Etemadi,2007).

\section{Research theories and background}

Bankruptcy always has diverted wide range of individuals, organizations and the general part of the community. It is very difficult to provide an accurate definition for interest groups bankruptcy. But it can be claimed that it will be influenced bankruptcy phenomena more than others, Management, investors, creditors, competitors, and legal institutions. Investors with predict bankruptcy, not only to prevent the risk of burning their capital, but its use as a tool to reduce the risk of your portfolio (Etemadi,2007 ). Hence, They are the ways that could estimate the company's financial bankruptcy, because in case of bankruptcy, stock price of 
companies sharply decreases(Rasoulzadeh,2000). Predicting financial bankruptcy has been taken into consideration widely in Accounting and financial field. Such research has great impact on lending decisions for creditors and also their profitability. Before creditors respond to corporate loans demand they should be able to predict possibility of company's bankruptcy.

Therefore, accurate and timely prediction of bankruptcy has a significant impact on the process and the Continuance of credit institutions (Arabmazar et al,2007 ).

Commercial units managers also can be informed timely of the risk of bankruptcy adopt to For preventive measures which prevent bankruptcy (Etemadi,2007). From a management viewpoint, tools predicting financial bankruptcy provides this possibility to adoption timely strategic actions and avoided from bankruptcy(Arabmazar et al,2007).Bankruptcy prediction models is one of the techniques and tools to predict the future state of the company's in that likelihood of bankruptcy estimate with compositions a group of financial ratio.

Bankruptcy prediction models can be classified in three groups, statistical modeling, artificial intelligence, and theoretical. Statistical models themselves are divided into two groups, univariate and multivariate. Multivariate statistical model is composed of Multiple discriminant analysis models, linear probability, logit, probit, the total cumulative and Partial adjustment processes.

Artificial neural networks, genetic algorithms, recursive Afraz, rough sets, support vector machines, Sion-based reasoning and fuzzy logic, are composed artificial intelligence techniques

and theoretical models is also including criterion analysis of sheet / entropy theory, Bankruptcy theory of gambling, Cash management theory and theories of credit risk.(Firouziyan et al,2010)

Komijani et al (2005) conducted a research titled "The conditional likelihood of optimal model to predict the economic bankruptcy of companies in Iran". The results showed four multivariate probit and logit models with explanatory variables current assets to current liabilities,gross profit to sales and net profit to current debt have maximum of predictive power than company economic bankruptcy in Iran. (Komijani et al,2005)Vadiee et al(2011)compared Ohlson logit analysis and multiple discriminant analysis fulmer models. The results showed Ohlson logit analysis model than multiple discriminant analysis Fulmer model have better than performance. Ohlson model prediction accuracy is for years $t, t-1$ and $\mathrm{t}-2$, respectively, $\% 96, \% 91$ and $\% 89$, While the fulmer model prediction accuracy is for years t, t-1 and t-2, respectively, \%85, \% 74and \%76.(Vadiee et al,2011)Houghton (1994) did a research titled" Accounting Data and the Prediction of Business Failure" using logistic regression to classify the companies studied. His model accuracy was for the first years to third respectively \%85.1, \%87.6 and \%82.6.Houghton in their study concluded that a better way the logit model to discriminate analysis techniques.(Houghton,1994)Aziz et al (1988) did a research titled "Bankruptcy prediction: an investigation of cash flow Models" to compared two model of Logit and Multiple-discriminant analysis models. The results showed 


\section{Macrothink}

better performance of logistic regression model, the model was designed based on multiple discriminant analysis.

The results showed better performance of designed model by the logistic regression model, in compare with designed model based on multiple discriminant analysis. Logit models have overall accuracy between $\% 79$ to $\% 92$ and was accuracy of discriminant analysis between 73 to 89 percent (Aziz et al,1988).Lennox(1999)examined the reasons for the bankruptcy of a sample including 949 English companies since 1978-1994. Based on Lennox, the most important bankruptcy factors include profitability, financial leverage, cash flows, company size, industrial section, and economic cycles. The results showed higher accuracy of Logit and Probit models, compared with discriminant analysis in predicting companies' failures (Lennox, 1999).

Thus, this study to predict the bankruptcy likelihood of manufacturing firms in Tehran Stock Exchange, comparing the results of the application of 3 statistical models to predict bankruptcy such Logit, Probit, and Multiple-discriminant analysis.

\section{Methodology}

In this study, we use to predict corporate bankruptcy from three statistical models, logit, probit, and multiple discriminant analysis. Logit model has wide applications in predicting business failures. By allocating some weights to independent variables, this model predicts the ranking of every sample company. This ranking is used for determining membership likelihood in a definite group. Success or failure likelihood in this model is calculated by the following formula:

$$
p(z)=\frac{1}{1+\mathrm{e}^{-\mathrm{z}}}=\frac{1}{1+\mathrm{e}^{-\left(\mathrm{a}+\mathrm{b}_{1} \mathrm{x}_{1}+\ldots+\mathrm{b}_{\mathrm{n}} x_{n}\right)}}
$$

Where, $X_{\mathrm{i}}(\mathrm{i}=1, \ldots, \mathrm{n})$ shows independent variables, and $a$ and $b_{i}(\mathrm{i}=1, \ldots, \mathrm{n})$ are estimated parameters of the model. $P(z)$ likelihood is a number between 0 and 1 .If $Z$ move into $-\infty$, $p(z)$ will tend to zero and if $Z$ move into $+\infty, p(z)$ will tend to 1 .when $Z$ is equal to zero, the resulting likelihood equal to0.5.Logit analysis instead of predicting what will be actually event or not, predicted likelihood of the event. Thus dependent variable could encompass to include a range of values between 0 and 1 .

Probit model is used when the dependent variable, was qualitative and be able to provide only the values 0 and 1. (Such as bankruptcy and non-bankruptcy)Probit models are mostly similar to Logit models. But, the former uses cumulative likelihood function which is normal rather than cumulative logistic function.

$$
\begin{gathered}
\mathrm{P}\left(X_{\mathrm{i}}, \hat{\mathrm{a}}\right)=F\left(a+\hat{\mathrm{a}} X_{\mathrm{i}}\right) \\
F\left(a+\hat{\mathrm{a}} X_{\mathrm{i}}\right)=\int_{-\infty}^{\hat{a}+\hat{a} x_{i}} \frac{1}{(2 \pi)^{\frac{1}{2}}} e^{\frac{-x^{2}}{2}} d z
\end{gathered}
$$


Multiple-discriminant analysis is a multivariable method in which the phenomena are divided into distinct groups with different qualities. This study aimed to recognize the differences among the groups and predict the likelihood of a company's dependency to a specific group. For such predictions, some quantitative independent variables were used.Thus, a basic prerequisite for MDA is that a data item could be classified into two or more groups. In the context of ratio-based models for signaling corporate collapse, two groups are readily identified: the first group includes companies that have collapsed and the second group contains companies that are still a going concern. The data item is therefore a company.In this method, a company was attributed to a bankrupt or non-bankrupt group according to its achieved score and the maximum similarities.

Classification was done based on optimum shortcut point, identified for Multivariable-discriminant analysis model. If the score of a company was lower than shortcut point, it was regarded as a non-bankrupt company. The mathematical equation is referred to as the discriminant function, and the financial ratios are called discriminating variables. Equation 1 gives the general specification of the MDA-based model.

$$
F_{\mathrm{km}}=\mathrm{u}_{0}+\mathrm{u}_{1} \mathrm{x}_{1 \mathrm{~km}}+\mathrm{u}_{2} \mathrm{x}_{2 \mathrm{~km}}+\cdots+\mathrm{u}_{\mathrm{p}} \mathrm{x}_{\mathrm{pkm}}
$$

$F_{\mathrm{km}}$ :The value that the discriminant function generates for company ' $\mathrm{m}$ ' in group ' $\mathrm{k}$ ', where ' $\mathrm{k}$ ' represents either the group of collapsed companies or the group of non-collapsed companies. ' $\mathrm{fkm}$ ' is also known as the score.

$\mathrm{x}_{\mathrm{ikm}}$ : The value for the financial ratio ' $\mathrm{i}$ ' for company ' $\mathrm{m}$ ' in group ' $\mathrm{k}$ '.

$U_{i}$ :Coefficients associated with each financial ratio ' $\mathrm{x}_{\mathrm{ikm}}$ '.

$\mathrm{u}_{0}$ :is the constant term or the intercept.

The first time Altman (1968) suggested multiple discriminant analysis method for predicting corporate failure. This study a lot attention because for the first time in bankruptcy prediction had modeling more than one variable.

\section{1 Variables}

To identify the most important financial ratios for selecting main variables of the study, principal component analysis was used. In principal component analysis, convert allowing a large number of initial variables into a small number of new variables that the same first several principal components are to reviewed so that the new variables have a large share of the whole variance. At first Spss, selects combination of variables that their correlations are the highest amount in total variance. This collection makes first factor. Second Factor is collections of variables that have the highest contribution in explaining the remaining variance. This approach will apply to select the third, fourth and subsequent factors. Correlation of each variable with each factor is called factor lodding and their Value fluctuates between -1 and +1 . Variance explained by each factor equal to the square of the factor lodding. This variance is called the specific value. The first specific value of the highest and is greater than 1 . In analyzing principal components, the values over 1 were regarded and used as the most 


\section{Macrothink

significant specific values.To choose the number of main variables can be considered proportional of the change total percentage cumulative so that the this main components, 80 or 90 percent, to express initial changes. Thus After examining 22 financial ratios, 7 factors was identified.

Independent variables of the study include:

-Return on equity (ROE)

-Debt ratio

-Debt cover ratio

-Collection period

-Inventory turnover

-Debt to equity ratio

-Product to working capital ratio

-Dependent variable was the likelihood of bankruptcy or non- bankruptcy occurrence.

\section{Results}

Statistical population of the study included all manufacturing companies accepted in Stock Exchange of Tehran since 2000-2010. To measure model fitness, the data of 55 bankrupt and 134 non- bankrupt companies were used. Bankruptcy measure in this study was Act 141 of Business Law in Iran, based on which the firms with minimum accumulated loss, equal with the half of their capital must declare bankruptcy or capital loss. Sample selection of nonbankrupt companies was based on the following conditions:

1. The companies should be manufacturing.

2. Their fiscal year should end in September.

3. Financial information of the companies should be accessible.

4.They should have 10 successive years of activity in Stock Exchange of Tehran since 2000- 2010.

\section{1. logit model}

Logit regression model fitness was tested based on the following equation:

$$
\begin{gathered}
P\left(v_{i t}=1\right)=\frac{\mathrm{e}^{Z_{i t}}}{1+\mathrm{e}^{Z_{i t}}} \\
Z_{i t}=\theta_{0}+\sum_{j=1}^{8} \theta_{j} x j_{i t}+\varepsilon
\end{gathered}
$$


Table 1. Regression statistics

\begin{tabular}{|l|l|l|}
\hline $\begin{array}{l}\text { Coefficient of determination } \\
\text { Nagelkerke }\end{array}$ & $\begin{array}{l}\text { Coefficient of determination } \\
\text { Cox \& Snell }\end{array}$ & -2 Log likelihood \\
\hline 0.273 & 0.191 & 187.898 \\
\hline
\end{tabular}

Table 2. Significant regression test

\begin{tabular}{|c|c|c|}
\hline Sig. & $\mathrm{df}$ & Chi-square \\
\hline 0.000 & 7 & 40.055 \\
\hline
\end{tabular}

Table 3. Logistic regression coefficients

\begin{tabular}{|l|r|r|l|l|l|}
\hline & Sig. & df & Wald Statistic & Standard deviation & Coefficient \\
\hline ROE & 0.000 & 1.000 & 14.264 & 0.006 & -0.024 \\
\hline Inventory turnover & 0.09 & 1.000 & 2.821 & 0.002 & 0.003 \\
\hline Collection period & 0.761 & 1.000 & 0.092 & 0.001 & 0.0004 \\
\hline Product of working capital ratio & 0.927 & 1.000 & 0.008 & 0.007 & 0.001 \\
\hline Debt ratio & 0.005 & 1.000 & 7.983 & 0.078 & 0.220 \\
\hline Debt to equity ratio & 0.004 & 1.000 & 8.214 & 0.080 & -0.228 \\
\hline Debt coverage ratio & 0.691 & 1.000 & 0.158 & 0.012 & -0.005 \\
\hline Constant & 0.054 & 1.000 & 3.723 & 252.742 & 487.667 \\
\hline
\end{tabular}

According to likelihood value in significance test $(\mathrm{P}=0.000)$ shown in Table 1 and,2 it can be concluded that the model is statistically significant and due to its resulted determination coefficient it identifies $\% 27$ of distribution. Table 3 shows logistic regression coefficients and gives the following formula:

$$
\begin{gathered}
Z_{i t}=487.667-0.024 X_{1}+0.003 X_{2}+0.0004 X_{3}+0.001 X_{4}+0.220 X_{5}-0.228 X_{6} \\
-0.005 X_{7}+\varepsilon
\end{gathered}
$$

\begin{tabular}{|c|c|c|c|c|}
\hline & & \multicolumn{2}{|c|}{ Estimation of bankruptcy } & \multirow[b]{2}{*}{ Percentage of accuracy } \\
\hline & & 0 & 1 & \\
\hline \multirow[b]{2}{*}{ Observed Bankruptcy } & 0 & 133 & 1 & 99.3 \\
\hline & 1 & 35 & 20 & 36.4 \\
\hline \multicolumn{4}{|l|}{ Percent } & 81.0 \\
\hline
\end{tabular}

Table 4. To accurately estimate of bankruptcy

Estimation accuracy was $\% 81$. For non-bankrupt companies, it was $\% 99$ and it was $\% 36$ for bankrupt companies shown in Table4. 


\subsection{Probit model}

Probit regression model was measured based on the following equation:

$$
P\left(v_{i t}=1\right)=N P\left(\theta_{0}+\sum_{j=1}^{8} \theta_{j} x j_{i t}+\varepsilon\right)
$$

Table 5. Significant regression test

\begin{tabular}{|l|l|ll|}
\hline Sig. & df & & Chi-square \\
\hline 0.000 & 7 & 34.984 & \\
\hline
\end{tabular}

Table 6. Probit regression coefficients

\begin{tabular}{|l|r|r|l|l|l|}
\hline & Sig. & df & Wald Statistic & \multicolumn{1}{|c|}{ Standard deviation } & \multicolumn{1}{c|}{ Coefficient } \\
\hline Intercept & 0.279 & 1 & 1.171 & 124.7689 & -135.00 \\
\hline ROE & 0.000 & 1 & 13.910 & 0.0027 & 0.0102 \\
\hline Inventory turnover & 0.059 & 1 & 3.557 & 0.0010 & -0.0019 \\
\hline Collection period & 0.924 & 1 & 0.009 & 0.0007 & -0.0001 \\
\hline Product of working capital ratio & 0.892 & 1 & 0.018 & 0.0040 & -0.0005 \\
\hline Debt ratio & 0.012 & 1 & 6.343 & 0.0363 & -0.0915 \\
\hline Debt to equity ratio & 0.009 & 1 & 6.856 & 0.0283 & 0.0742 \\
\hline Debt coverage ratio & 0.724 & 1 & 0.124 & 0.0069 & 0.0024 \\
\hline
\end{tabular}

According to likelihood value in significance test $(\mathrm{P}=0.000)$ shown in Table5, it can be concluded that the model is statistically significant. Table 6 shows probit regression coefficients and gives the following formula:

$$
\begin{aligned}
P\left(v_{i t}=1\right) & =N P\left(135-0.0102 X_{1}+0.0019 X_{2}+0.0001 \mathrm{X}_{3}+0.0005 \mathrm{X}_{4}+0.0915 \mathrm{X}_{5}\right. \\
& -0.0742 \mathrm{X}_{6}-0.0024 \mathrm{X}_{7}+\varepsilon
\end{aligned}
$$

Table 7. To accurately estimate of bankruptcy

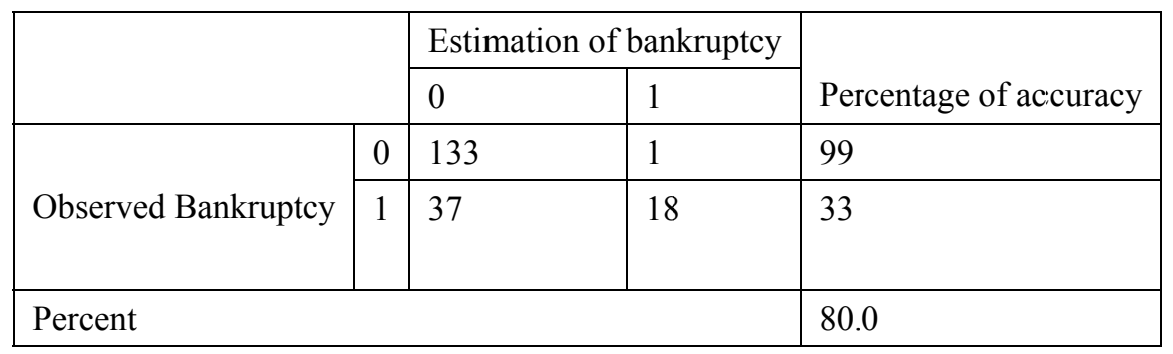




\section{Macrothink}

Asian Journal of Finance \& Accounting

ISSN 1946-052X

2013, Vol. 5, No. 1

Estimation accuracy was $80 \%$. For non-bankrupt companies, it was $\% 99$ and $\% 33$ for bankrupt companies, shown in Table7.

4.3 Multiple-discriminant model

Multiple-discriminant model was examined based on the following equation:

$$
v_{i t}=b_{0}+\sum_{j=1}^{8} b_{j} x j_{i t}
$$

Table 8 . Table eigenvalue function

\begin{tabular}{|l|c|l|l|}
\hline Canonical Correlation & Cumulative \% & $\%$ of Variance & Eigenvalue \\
\hline 0.220 & 100.0 & 100.0 & $0.051^{\mathrm{a}}$ \\
\hline
\end{tabular}

Table 9. Table meaningful test

\begin{tabular}{|l|l|l|l|}
\hline Sig. & df & Chi-square & Wilks' Lambda \\
\hline 0.243 & 7 & 9.130 & 0.951 \\
\hline
\end{tabular}

Table 10. Table non-standardized coefficient Focal functions

\begin{tabular}{|l|l|}
\hline & Function \\
\hline & $\mathbf{1}$ \\
\hline ROE & -0.001 \\
\hline Inventory turnover & 0.001 \\
\hline Collection period & 0.003 \\
\hline Product to working capital ratio & 0.001 \\
\hline Debt ratio & 0.121 \\
\hline Debt to equity ratio & -0.011 \\
\hline Debt cover ratio & -0.015 \\
\hline (Constant) & -55.071 \\
\hline
\end{tabular}

Regarding the likelihood value in significance test $(\mathrm{P}=0.243)$ and comparing it with significance level, it can be said that the model is statistically insignificant, as shown in Table 8 and 9.

Table 10 shows non-standardized coefficient Focal functions and gives the following formula: 


$$
\begin{gathered}
v_{i t}=-55.07-0.001 X_{1}+0.001 X_{2}+0.003 X_{3}+0.001 X_{4}+0.121 X_{5}-0.011 \mathrm{X}_{6} \\
-0.015 X_{7}
\end{gathered}
$$

Table 11. To accurately estimate of bankruptcy

\begin{tabular}{|l|l|l|l|l|}
\hline \multicolumn{2}{|c|}{} & \multicolumn{2}{|l|}{ Estimation of bankruptcy } & \multirow{2}{*}{ Percentage of accuracy } \\
\cline { 2 - 5 } \multicolumn{2}{|c|}{} & 0 & 112 & 83.6 \\
\hline \multirow{3}{*}{ Observed Bankruptcy } & 0 & 112 & 22 & 36.4 \\
\cline { 2 - 4 } & 1 & 35 & 20 & 69.8 \\
\hline Percent & & & 1 \\
\hline
\end{tabular}

Estimation accuracy in the sample is shown in Table11. Estimation accuracy was \%70. It was $\% 84$ for non-bankrupt companies and $\% 36$ for bankrupt companies.

Table 12. Ratio test for comparing the models of efficiency and Multiple-discriminant regression.

\begin{tabular}{|c|l|l|l|}
\hline & Accuracy & $\mathrm{p}$ - value & $\mathrm{Z}$ test \\
\cline { 1 - 2 } Multiple discriminant analysis & $69.8 \%$ & & \\
\cline { 1 - 2 } Data envelopment analysis & $72.0 \%$ & 0.325 & \multirow{2}{*}{0.453} \\
\hline
\end{tabular}

Table. 12 shows the Ratio test for comparing the models of efficiency and Multiple-discriminant regression. The results show that the accuracy of Multiple-discriminant regression is not higher. Also,Z test results don't confirm a significant difference between Multiple-discriminant regression and DEA.

\section{Conclusion}

In this study we compared predicting power of Logit, probit and multivariate discriminant analysis models to predict bankruptcy. The results showed that predicting power of Logit model was $\% 81$, for identify non-bankrupt companies $\% 99$ and $\% 36$ for bankrupt companies.

Logit model, Could predict from 134 non-bankrupt companies, 134 companies correctly. This model from 55 bankrupt company, have been able to predict bankruptcy 20 companies that indicative high power logit model in prediction of corporate bankruptcy.

The results of Probit model confirm that can predict power this model in the prediction of corporate bankruptcy has \%80.accuracy of the Probit models to identify non-bankrupt companies is \%99 and for bankrupt companies is 33 percent.This model from 134 non-bankrupt companies were able to predict correctly133 companies and also from 55 bankrupt companies has been able to correctly predict bankruptcy 18 company.The results showed that Probit model to identify bankruptcy firms, no significant difference in the logit model. 


\section{Macrothink}

The results of the Multiple discriminant analysis model showed that accuracy of this model is about \%70. Accuracy of the Discriminant analysis models \%83.6 for the distinction of corporate bankruptcy and $\% 36.4$ for the prediction of corporate bankruptcy.

This model could predict only 112 companies from 134 non-bankrupt firms, to predict correctly. The results show that Multiple discriminant analysis model has high accuracy in recognition of bankrupt companies in compared to logit model level and has much better performance compared to probit model. The research results show that the overall accuracy and predictive power of logistic regression is higher than the other two models. Probit model has a performance near to logit model but in lower level, Multiple discriminant analysis also has a lower predictive power in compare to two other models. But in contrast, to identify bankrupt companies probit model has better performance.

\section{References}

Arabmazar, M., \& Akbari, M. (2007)Predicting corporate bankruptcy using neural networks, Accountant monthly, 200, 34

Aziz, A., Emanuel, D., \& Lawson, H. (1988). Bankruptcy prediction:an investigation of cash flow Models. Journal of Management Studies, 25(5), 437-419.

Brigam,W. (2003). Financial management. Translated by Abdeh, H, Pishbord,PP21

Ching-Ching, Y., Der Jang, Ch., \& Ming, Fu, H. (2010). A hybrid approach of DEA ، rough set and support vector machines for business failure prediction. Expert System with Application, 37(2), 1535-1541.

Etemadi, H., \& Dehkordi, H. (2007). A review of bankruptcy prediction models. Accountant monthly, 5, 40 .

Firouzian, M., Javid, D., \& Najmodini, N. (2010). Application of genetic algorithms in the bankruptcy prediction and compared with Altman $\mathrm{Z}$ model Companies listed on the Tehran Stock Exchange. Review of accounting and auditing in Iran, 65, 100.

Houghton, K. A. (1994). Accounting Data and the Prediction of Business Failure: the Setting of Priors and the Age of Data. Journal of Accounting Research, 22(1), 361-368. http://dx.doi.org/10.2307/2490717

Komijani, A., \& Saadatfar, J. (2005). The conditional likelihood of optimal model to predict the economic bankruptcy of companies in Iran. Journal of Human Sciences, 57, 28-3.

Lennox, C. (1999). Identifying failing companies: A re-evaluation of the Logit, Probit, and DEA approaches. Journal of Economics and Business, 51(4), 347-364. http://dx.doi.org/10.1016/S0148-6195(99)00009-0

Rasoulzadeh, M. (2000). Application Altman model at status determination bankruptcy companies. Tadbir monthly, 120, 100.

Rekabdar,G. H., Chinipardaz, R., \& Solimani, B. (2006). The Discriminant analysis of mixed in prediction of bankruptcy. Journal of Applied Mathematics, 12, 25-15. 


\section{Macrothink}

Tonatiuh Pena, C. Serafin Martinez, \& J. Bolanle, A. (2009). Learning Techniques. Banco de Mexico Working Paper. Bankruptcy Prediction: A Comparison of Some Statistical Models.

Vadiee, M., \& Miresmaeeli, H. (2011). Predicting bankruptcy by using ohlson logit model analysis and multiple discriminant analysis Fulmer And compare them. Accounting and audit research, 13, 23-1.

\section{Copyright Disclaimer}

Copyright reserved by Maryam Khalili Araghi and Sara Makvandi.

This article is an open-access article distributed under the terms and conditions of the Creative Commons Attribution license (http://creativecommons.org/licenses/by/3.0/). 